\title{
Formação de professores e formação humana: não é só necessária, mas possível
}

\section{Teacher training and human formation: not only necessary but possible}

\author{
Suzana Cini Freitas Nicolodi ${ }^{1}$ \\ Valentim da Silva ${ }^{1}$
}

\begin{abstract}
RESUMO
O texto a seguir dialoga sobre a experiência vivenciada e integrada entre estudantes de uma turma do Curso de Licenciatura em Ciências e de uma turma do $9^{\circ}$ ano do ensino fundamental no litoral paranaense. Compreendendo a importância de buscar a ruptura epistemológica com o paradigma educacional dominante, buscou-se por novos sentidos e maneiras de fazer e fazer-se na docência. Em docência compartilhada, via aprendizagem por projetos e, especialmente, apoiados na pedagogia freireana, os autores apresentam suas percepções sobre os processos de mediação na formação de professores e na formação humana. Apontam como principais aprendizados: a necessidade de intervenção nos espaços formativos; o reconhecimento do contexto local para a ressignificação de conceitos e valores; a garantia de espaços de escuta e de fala; e, sobretudo, o cuidado afetivo com o outro.

Palavras-chave: docência compartilhada; aprendizagem por projetos; trama conceitual freireana.
\end{abstract}

\begin{abstract}
The following text dialogues with the integrated and lived experience between students of a Bachelor of Science Degree course and students of the $9^{\text {th }}$ grade from a middle school in Paraná state coast, Brazil. Understanding the importance of seeking for the epistemological break with the dominant educational paradigm, new meanings were sought, ways of doing and being
\end{abstract}

DOI: $10.1590 / 0104-4060.47207$

1 Universidade Federal do Paraná. Setor Litoral. Matinhos, Paraná, Brasil. Rua Jaguariaíva, nº 512.CEP: 83.260-000.E-mails: suzanacfn@yahoo.com.br e valentimdasilva@gmail.com 
in academic teaching. In shared teaching, through learning projects, specially based on Paulo Freire's pedagogy, the authors present their perceptions of mediation processes in teacher education and human formation. The main indicated sources of learning are the need for intervention in the formative spaces; the recognition of the local context to reframe concepts and values; the guarantee of listening and speech spaces and, above all, the emotional care for the other.

Keywords: shared teaching; learning through projects; Paulo Freire's conceptual plot.

\section{Para início de conversa}

Compreendemos que o cenário atual, na Educação brasileira, é de busca por alternativas de ruptura com processos tradicionais de formação de professores que enfatizam abordagens teóricas sobre as abordagens práticas. Além disso, sentimos a necessidade de que tais alternativas contemplem a formação profissional integrada à formação das pessoas.

Como ressalta António Nóvoa (1995), estamos no cerne do processo identitário da profissão docente, pois, "o professor é a pessoa, e uma parte importante da pessoa é o professor”. (NÓVOA, 1995, p. 15). Nesse entendimento, os conceitos emancipatórios podem ser ressignificados a partir do sujeito, que, também, é o educador.

Apresentamos a seguir a proposta de uma alternativa de ruptura com o modelo educacional dominante na formação inicial de professores, explorando seu desenvolvimento, desafios e aprendizados que a envolveram.

\section{Contextualizando a experiência}

O Setor Litoral da Universidade Federal do Paraná (UFPR Litoral), situado no município de Matinhos-PR, realiza ações alicerçadas no Projeto Político-Pedagógico (UNIVERSIDADE FEDERAL DO PARANÁ, 2008) que envolvem possibilidades de atuar com metodologias que possibilitem uma visão interdisciplinar da construção do conhecimento, que buscam o cuidado com a formação humana. Almeja-se viabilizar a construção de processos de ensino e aprendizagem articulados ao contexto local - litoral paranaense. Desse modo, se 
oportuniza espaços de ações pedagógicas para educadores e educandos, desde a fase inicial nos cursos de ensino superior, relacionado a questões ambientais, culturais, políticas, econômicas e sociais dessa região. Essa intencionalidade estabelece relações práxiológicas nas diferentes ações didáticas planejadas, envolvendo os espaços e agentes educacionais que integram o coletivo da UFPR Litoral e as diversas esferas educacionais que compõem a comunidade.

No que diz respeito à condução desenvolvida por três professores atuando em docência compartilhada (CITOLIN, 2013), percebemos que o fazer pedagógico docente

[...] envolve planejamento participativo, diálogo, troca de ideias e de concepções, atuação conjunta em sala de aula, com resolução de imprevistos de modo colaborativo. Resulta rever "erros", modificar posturas e aprender com o colega, reconhecendo-o como produtor do conhecimento. (CITOLIN, 2013, p. 118).

Na docência compartilhada não existe um único professor designado responsável, mas posicionamentos e intervenções emergem como resultado das interações entre todos no espaço de trabalho. Através do planejamento coletivo, as decisões são compartilhadas e relacionam-se com as experiências que cooperativamente se deseja vivenciar. Nesse sentido, a docência compartilhada só se efetiva quando os participantes estão abertos para o diálogo na ação-reflexão-ação.

Entendemos o paradigma educacional emergente como agregador e potencializador das aprendizagens, valorizando as diferenças e aproximações na proposta pedagógica, centrada na aprendizagem por projetos. (KELLER-FRANCO; MASETTO, 2012). A proposição curricular via aprendizagem por projetos possibilita ao estudante construir conhecimento, integrando as diferentes áreas, estabelecendo ações na realidade.

Os educandos são estimulados a perceberem criticamente a realidade, compreendendo os vários elementos que a estruturam para que possam estabelecer ações de intervenção nas situações locais e nas relações entre pessoas, saberes e instituições, tendo como palco a UFPR Litoral, as escolas da rede pública e a comunidade da região litorânea.

Lembramos que,

[...] quanto mais as pessoas participarem do seu próprio processo de formação, maior será sua participação no processo de definir que tipo 
de produção produzir, e para que e por que, e maior será também sua participação no seu próprio desenvolvimento. Quanto mais as pessoas se tornarem elas mesmas, melhor será a democracia. Quanto menos perguntarmos às pessoas o que desejam e a respeito de suas expectativas, menos será a democracia. (HORTON; FREIRE, 2003, p. 149).

Com a compreensão das intencionalidades aqui descritas, realizamos o convite à turma do $3^{\circ}$ ano do Curso de Licenciatura em Ciências da UFPR/ Litoral para realizar uma experiência de formação fora do tradicional espaço universitário. Nossa compreensão foi que existem acontecimentos próprios da escola que só acontecem na escola. Esse era o desejo que nos movia; que os licenciandos tivessem a oportunidade de vivenciar e experienciar a vida docente e a escolar no seu cotidiano, seus encantos e desafios, de forma significativa antes mesmo de terminarem sua formação. Desse modo, nos semestres de 2013/2 e 2014/1 desenvolvemos os módulos ${ }^{2}$ curriculares, sendo que os pressupostos na ementa apontavam a necessidade de abordar a prática de ensino em escolas locais a partir da relação com o ensino e a aprendizagem e suas implicações.

Para consolidar as intencionalidades dos módulos, firmamos a parceria, via direção, com o Colégio Estadual Sertãozinho, no município de Matinhos-PR, o qual nos cedeu espaço e abriu as portas para o movimento que denominamos de Universidade Escola. No Colégio Estadual Sertãozinho a proposta foi acolhida pela professora de Ciências, que abriu espaço para um trabalho compartilhado com a turma do $9^{\circ}$ ano. Pudemos, então, integrar os currículos dos estudantes do $3^{\circ}$ ano de Licenciatura em Ciências com as aulas de Ciências do $9^{\circ}$ ano noturno do ensino fundamental.

Como Freire (1979) ensina,

[...] procurávamos uma metodologia que fosse um instrumento do educando, e não somente do educador, e que identificasse - como fazia notar acertadamente um sociólogo brasileiro - o conteúdo da aprendizagem com o processo mesmo de aprender. (FREIRE, 1979, p. 23).

Acreditávamos que essa metodologia e experiência poderiam minimizar os impactos próprios do início de carreira, além de oportunizar reflexões acerca

2 Vivências de docência, Relação ciências e sociedade e Prática de Ensino (LICIEN009); Vivências de docência, Relação ciências e meio ambiente e Prática de Ensino (LICIEN011); Estágio Supervisionado IV (LICIEN010). Relativos ao $5^{\circ}$ e $6^{\circ}$ semestre ( $3^{\circ}$ ano) do Curso de Licenciatura em Ciências do Setor Litoral da UFPR (2011). 
das práticas pedagógicas e reforçar entendimentos sobre os desafios do fazer docente. Desejávamos oportunizar uma experiência tal como Bondía (2002, p. 19) sugere: "[...] que exploremos juntos outra possibilidade, digamos mais existencial (sem ser existencialista) e mais estética (sem ser esteticista), a saber, pensar a educação a partir do par experiência/sentido". Esperávamos que ocorresse uma educação que fizesse sentido para os estudantes universitários, para os estudantes da escola e, também, para nós.

\section{$O$ caminho se faz caminhando: o fazer docente se faz fazendo-se docente}

A abordagem metodológica freireana considera o contexto das escolas, do local/regional e os saberes dos sujeitos, fundamentada na concepção epistemológica emancipatória, na problematização e na conscientização, em movimentos que possibilitam o empoderamento dos sujeitos no processo. (FREIRE, 1979).

E assim, sentimos a necessidade de atuar sobre a realidade escolar para vivenciá-la. A interação com o mundo escolar teve como base o planejamento que oportunizou a organização e melhor otimização dos espaços e dos tempos dessa integração universidade-escola.

Os processos iniciais respaldaram-se nos materiais já disponíveis na escola. Por referência, buscamos analisar criticamente os livros de Ciências adotados pelos professores e pelas escolas, o guia do livro didático de Ciências (BRASIL, 2012); os Parâmetros Curriculares Nacionais (PNCs) de Ciências Naturais dos anos finais do ensino fundamental (BRASIL, 1997); as diretrizes curriculares da educação básica - o ensino de Ciências no estado do Paraná (PARANÁ, 2008); os objetivos previstos no Projeto Pedagógico do Curso de Licenciatura em Ciências (UNIVERSIDADE FEDERAL DO PARANÁ, 2011) e do Projeto Político-Pedagógico do Setor Litoral da Universidade Federal do Paraná (UNIVERSIDADE FEDERAL DO PARANÁ, 2008). Procuramos, ainda, compreender a realidade local envolvendo a escola e a comunidade.

Os processos que relacionam a universidade e a escola aconteceram em três encontros semanais, sendo dois destinados a abordagens teóricas mencionadas, referentes às ementas do curso de Ciências e retorno/planejamento/avaliação coletiva - de como teria sido a execução do planejamento. $\mathrm{O}$ terceiro momento foi destinado ao planejamento e encaminhamentos integrados com os estudantes da universidade e do Colégio Estadual Sertãozinho.

Assim, a proposta da turma de licenciatura em Ciências foi construir 
um projeto "guarda-chuva" para que pudéssemos guiar os encaminhamentos nos encontros coletivos entre os graduandos. Para atendermos essa demanda utilizamos a abordagem teórica metodológica proposta por Saul e Saul (2013), que estimula o uso da Trama Conceitual Freireana para estabelecer as relações conceituais.

Freire nos desafia a não olhar as palavras isoladamente, mas na moldura das tramas às quais elas se encontram imbricadas. Isso permite uma compreensão totalizante e dinâmica dos conceitos, explorando suas relações de interdependência e diferentes ângulos de explicação e análise. (SAUL; SAUL, 2013, p. 107).

Nesse sentido, as atividades relacionadas às abordagens conceituais das ementas dos módulos geraram a Trama Conceitual Freireana.

FIGURA 1 - TRAMA CONCEITUAL FREIREANA - HORTA NA ESCOLA: ESPAÇOS EDUCACIONAIS SUSTENTÁVEIS

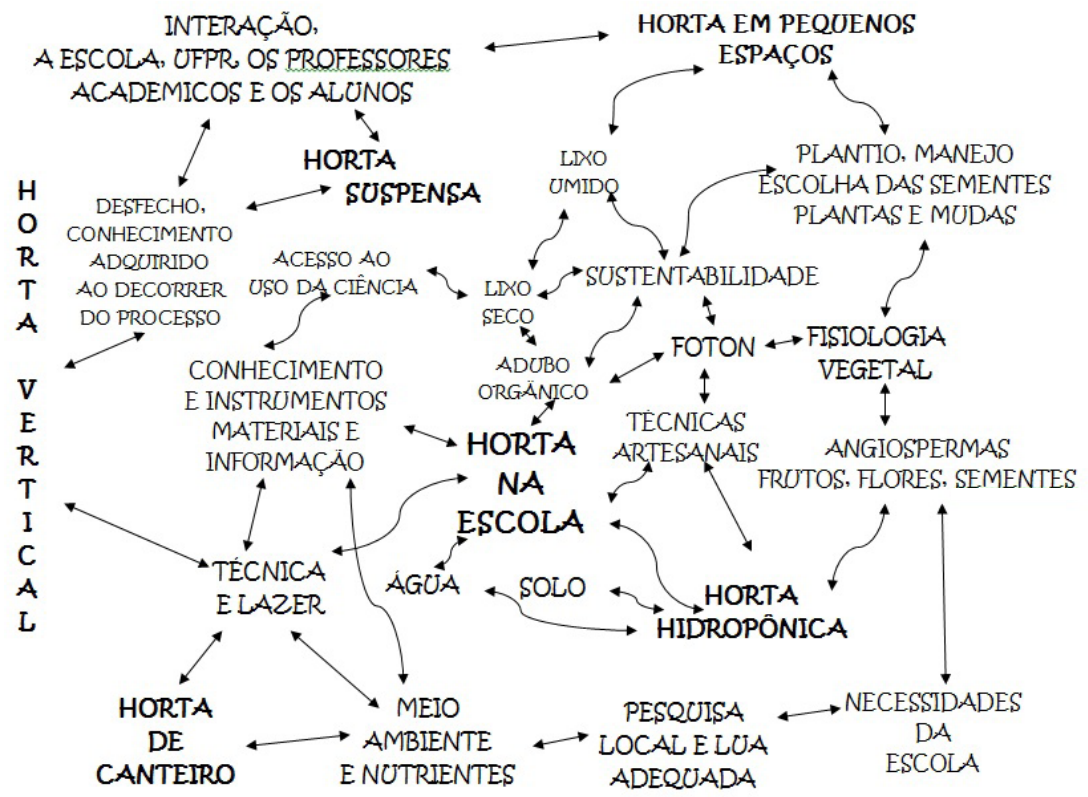

FONTE: Estudantes do $3^{\circ}$ ano do Curso de Licenciatura em Ciências - segundo semestre (2015). 
O exercício foi inspirado, também, nos ensinamentos do próprio Freire (1979), que elucida que

[...] no nosso método, a codificação, a princípio, toma a forma de uma fotografia ou de um desenho que representa uma situação existencial real ou uma situação existencial construída pelos alunos. [...] O fim da descodificação é chegar a um nível crítico de conhecimento, começando pela experiência que o aluno tem de sua situação em seu "contexto real". (FREIRE, 1979, p. 18).

Na sequência, através das atividades integradas, foi desenvolvida, no terceiro momento, a Trama Conceitual Freireana com os estudantes de Ciências do $9^{\circ}$ ano. Desta proposição surgiram quatro subprojetos: horta hidropônica; horta em pequenos espaços; horta de canteiro; horta suspensa.

Observamos que a participação integrada possibilitou aos acadêmicos vivenciarem o papel docente sem as tensões próprias dos primeiros encontros no papel de professor, pois se sentiam salvaguardados pelos docentes mediadores da proposta. E nós, no papel de mediadores da aprendizagem, pudemos, gradualmente, nos distanciar do papel de professor responsável pela condução das atividades. Isso ocorreu na medida em que os estudantes passaram a interagir mais, permeados pelas iniciativas e proposições individuais nos coletivos e, neles, realizar a reflexão crítica das ações, que parece que os encorajou na auto-organização e nos encaminhamentos da proposta curricular.

Ainda, como papel fundamental, a docência compartilhada - agora também exercida pelos licenciandos - demonstrou a troca afetiva, um querer bem, um cuidado para com o outro, no sentido de estar junto. E nesses movimentos, percebidos também pelos estudantes do $9^{\circ}$ ano, evidenciou esse afeto coletivo, esse compromisso com o outro, com aquele que também é responsável pela "minha" aprendizagem. Esses movimentos nos proporcionaram a vivência defendida por Freire (1979, p. 39), quando destaca que "[...] ninguém educa ninguém, ninguém educa a si mesmo, os homens se educam entre si, mediatizados pelo mundo".

Entendemos que as práticas pedagógicas devam ser permeadas por compromisso com a reinvenção de uma escola em que, conforme Freire,

[...] os educandos descubram e sintam a alegria nela embutida que dela faz parte e que está sempre disposta a tornar todos quantos a ela se entreguem. A alegria na escola [...] não é só necessária, mas possível. Necessária 
porque gerando-se numa alegria maior - a alegria de viver -, a alegria na escola fortalece e estimula a alegria de viver [...] significa mudá-la, significa lutar para incrementar, melhorar, aprofundar a mudança. [...] Lutar pela alegria na escola é uma forma de lutar pela mudança no mundo. (SNYDERS, 1993, p. 10).

E nessa alegria necessária e possível, nos fizemos presentes na escola.

\section{Avaliação das práticas e vivências com os estudantes de Ciências}

Entendendo que a avaliação é uma oportunidade de corrigir e melhorar as práticas, propusemos aos licenciandos uma avaliação que propiciasse a articulação de alguns saberes valorizados por Freire, como a disponibilidade para o diálogo, a criticidade, o respeito aos saberes dos educandos, o saber escutar, a humildade, a tolerância e a convicção de que mudar é possível.

Também seguimos as orientações do Art. 24 da Lei de Diretrizes e Bases (LDB) (BRASIL, 1996, p. 58), que dispõe: “Avaliação contínua e cumulativa, do desempenho do aluno, com prevalência dos aspectos qualitativos sobre os quantitativos e dos resultados ao longo do período sobre eventuais provas finais".

Da mesma forma, fundamentamo-nos em Demo (2010), que pontua que

[...] a avaliação qualitativa pretende ultrapassar a avaliação quantitativa, sem dispensar esta. Entende que, no espaço educativo, os processos são mais relevantes que os produtos, não fazendo jus à realidade, se reduzida apenas às manifestações empiricamente mensuráveis. (DEMO, 2010, p. 106).

Nesse sentido, ao final do módulo de 2013/2, na intenção de sistematizar pontos considerados relevantes pelos acadêmicos de Ciências, realizamos um encontro focado em suas vivências, aprendizados e reflexões acerca do vivido ao longo do primeiro semestre na escola.

Como pontos fortes das práticas os estudantes de Ciências apontaram a montagem da horta, a interação, o companheirismo, o comprometimento e a troca de saberes com os estudantes da escola. Nestes termos, o conhecimento 
ganhou riqueza e a ressonância dos êxitos da intervenção nos leva a crer que, para além da antiga compreensão do fazer docente e do fazer escola, foi necessário mudar e ver que isso é possível.

Essa perspectiva encontra respaldo nas Diretrizes Curriculares Nacionais para a formação inicial em nível superior. (BRASIL, 2015). Reforçam que a formação de professores no país deve explicitar os aspectos políticos, filosóficos e éticos, orientados para uma formação comprometida com os valores democráticos e com o compromisso com o desenvolvimento das crianças e adolescentes inseridos na educação básica.

Essas premissas são apontadas no Art. $5^{\circ}$, que diz:

A formação de profissionais do magistério deve assegurar a base comum nacional, pautada pela concepção de educação como processo emancipatório e permanente, bem como pelo reconhecimento da especificidade do trabalho docente, que conduz à práxis como expressão da articulação entre teoria e prática e à exigência de que se leve em conta a realidade dos ambientes das instituições educativas da educação básica e da profissão, para que se possa conduzir o(a) egresso(a):

I - à integração e interdisciplinaridade curricular, dando significado e relevância aos conhecimentos e vivência da realidade social e cultural, consoantes às exigências da educação básica e da educação superior para o exercício da cidadania e qualificação para o trabalho. (BRASIL, 2015, não paginado).

Assim, houve a preocupação de envolvermo-nos em uma concepção de educação como processo emancipatório e permanente. Sendo que os diferentes ritmos, tempos e espaços, em face das dimensões psicossociais, histórico-culturais, afetivas, relacionais e interativas, permeiam os educandos e a ação pedagógica e nos levam a reconhecer metodologias pedagógicas que venham contribuir para o exercício profissional. Essas levam em consideração os fatores que permeiam a ação pedagógica na educação básica, incluindo o respeito às diferenças socioculturais que caracterizam os ambientes de trabalho.

Sobre a metodologia, os licenciandos refletiram que o fato de estarem atuando em coletivos de trabalho facilitou o processo, pois não se sentiram sozinhos, trabalharam juntos e atuaram como equipe. Nesse ponto, cabe considerar o conceito de intermediação pedagógica múltipla, trazido por Okada e Okada (2007) para compreender como ela pode favorecer o trabalho coletivo. Argumentam os autores que o aprendizado é potencializado não só pela inter- 
venção docente, mas, também, pela intervenção discente, na medida em que compartilham materiais, vivências, sugestões teóricas e opiniões.

$\mathrm{Na}$ "intermediação pedagógica múltipla", o aluno mediado torna-se um mediador pedagógico ao lado dos professores, seus auxiliares e colaboradores internos (colegas) e externos (autores consultados e palestrantes convidados) deixando de ser o único mediado. A intermediação pedagógica múltipla propicia a aprendizagem mediada por todos. Todos aprendem com todos (professores, monitores, tutores e alunos). Todos os participantes são corresponsáveis e coautores da produção coletiva de conhecimentos. E todos eles auxiliam um ao outro na sua produção individual. (OKADA; OKADA, 2007, p. 725).

Entretanto, como pontos dificultadores das práticas, relembram como foi desafiador lidar com a dispersão eventual dos estudantes e que, por vezes, sentiram um certo vácuo de orientações, com falta de direcionamento e deficiência teórica. É interessante refletir sobre este ponto, pois mesmo compreendendo que se prepararam para entrar na turma, tanto em relação ao planejamento quanto à fundamentação teórica, ainda perceberam deficiências.

Pensam que a fundamentação teórica foi importante, pertinente e responsável pelo direcionamento das atividades. Porém, embora detendo embasamento teórico mais extenso, sentiram dificuldades em respaldar os estudantes da escola devido à escassez de recursos, como a falta de acesso à internet e a restrição da biblioteca escolar, por exemplo. Nesse sentido, partiram das relações estabelecidas com os estudantes do $9^{\circ}$ ano para a execução das atividades.

No tocante ao planejamento, consideram que ele foi fundamental para o sucesso da experiência. Preocuparam-se em fornecer estímulos que possibilitassem a mobilização de interesse dos estudantes da escola e, ainda, que o conteúdo utilizado fosse relacionado com a realidade dos aprendizes. Ponderaram, ainda, que o planejamento é imprescindível e necessita ser detalhado para que o objetivo não se dilua, uma vez que é fácil perder-se no tempo; pois entendem que o improviso não dá conta da ação sistematizada, própria da condição escolar.

Lembraram que sentiram dificuldade no primeiro encontro e que, durante o processo, o interesse dos alunos foi aumentando na medida em que as hortas foram sendo construídas e os saberes e conhecimentos deles foram sendo valorizados. Foi preciso buscar o estudante na sua realidade.

Hernandez (2006) defende que o projeto curricular com possibilidades de sucesso é aquele que ensina os alunos a questionar sua própria realidade 
como estratégia para aprenderem. Essa condição é que lhes dará possibilidade para seguir aprendendo ao longo da vida. Para esta formação é preciso ensinar a gerar sentidos.

No relato sobre a execução do planejamento, os estudantes de Ciências elencaram várias impressões sobre o primeiro contato com os estudantes da escola. Entre elas, contaram que foi um momento impactante e preocupante, que gerou bastante ansiedade, pois perceberam o quanto precisavam, ainda, prepararem-se e planejar suas ações para que o desenvolvimento do projeto fosse satisfatório.

Essas situações de ansiedade foram diminuindo na medida em que os encontros foram acontecendo. Destacaram que, para tanto, foi importante buscar identificações com os estudantes da escola para que a horizontalidade professor/ estudante se instalasse. Além disso, procuraram desvincular o método de ensino tradicional de suas ações e agir no concreto, na construção efetiva de cada uma das diferentes hortas.

Lembraram ainda que a relação com os estudantes da escola foi estabelecida lançando mão de estratégias de aproximação refletindo que esta relação como também a participação podem ser negociáveis por meio da descoberta de interesses dos alunos e do equilíbrio entre a teoria e a prática nas proposições e até enquanto uma e outra tiveram suas fronteiras transgredidas.

Eles creem também que alguns pontos devem sofrer modificação para a continuidade do projeto, como um planejamento ainda mais minucioso. Os estudantes compreenderam que o ato de planejar é determinante para a realização de uma proposta com sucesso ou que o desleixo no planejar pode levar ao fracasso.

Como pontos a dar continuidade elencaram a relevância dos fundamentos teóricos estarem relacionados ao cotidiano dos estudantes para a construção do conhecimento se efetivar. Apontaram, além disso, a relevância de um direcionamento forte desde o início dos encontros, com dinamismo e movimento nas proposições, ofertando uma proposta diferenciada de estudo.

Nesse sentido, a mediação pedagógica ocupa papel de destaque, pois é na qualidade da interação que acontece entre os sujeitos envolvidos no processo educativo que ela se localiza. Por essa razão, a importância que ambos (mediadores e mediandos) estejam comprometidos com o processo, uma vez que "[...] só o aluno pode fazer aquilo que produz conhecimento, e o professor só pode fazer alguma coisa para que o também o aluno o faça". (CHARLOT, 2006, p. 15). Moraes (2003), quando define a mediação pedagógica, afirma que ela é

[...] um processo comunicacional, conversacional, de co-construção de significados, cujo objetivo é abrir e facilitar o diálogo e desenvolver a 
negociação significativa de processos e conteúdos a serem trabalhados nos ambientes educacionais, bem como incentivar a construção de um saber relacional, contextual, gerado na interação professor/aluno. (MORAES, 2003, p. 210).

Assim, o processo de mediação que se estabelece com qualidade pode provocar a reflexão, a autorreflexão, a tomada de consciência. Estimula a metacognição e, para atingi-la, é importante lançar mão de uma metodologia adequada, que propicie o fluxo das conversações e que mantenha o professor numa postura aberta, facilitadora, que se distancie de um comportamento de onipotência.

O docente da mediação é o que acompanha o trajeto do educando, transforma-se com ele, de forma a gerar sentidos ao longo desse caminho. Revê suas práticas constantemente, autotransforma-se, pois como nos lembra Freire e Shor (1987, p. 66), “[...] os estudantes não são uma frota de barcos tentando alcançar o professor que já terminou e os espera na praia. O professor é também um dos barcos da frota".

\section{Avaliação final: Grupo Focal}

Ao final do ano de trabalho com a turma, na intenção de fazer provocações que possibilitassem pensar juntos sobre as vivências e partilhas e, ainda, refletir sobre as aprendizagens individuais e coletivas adquiridas no processo, realizamos um Grupo Focal.

A questão geral lançada ao grupo foi: $O$ que esta vivência/experiência representou em sua formação? São as respostas dos estudantes a esta questão que compartilhamos daqui em diante.

Um deles explicitou que,

[...] ao refletir sobre avaliação, me dei conta de como avaliamos de forma cruel. Na minha vida mudou tudo, na forma de compreender a avaliação... e, sim, na vida. Precisamos considerar todo o entorno do ser, passei a me policiar em relação a isso. É preciso dar a possibilidade que todos falem e contem suas histórias. (Estudante B). 
Completando e ampliando essa posição, o Estudante C - que também é professor formador na Marinha - afirmou:

Tenho quatorze anos de adestramento no quartel, chego com a aula pronta e jogo lá... Ao chegar na Faculdade e me deparar com a possibilidade de emancipação do estudante, foi um choque! Como fazer? Precisava me censurar o tempo todo para dar espaço para os outros, isso foi muito conflitante, estava muito militarizado. O periodo com os estudantes -e não com soldados ou marinheiros - foi um desafio. Coloquei minha filha como termômetro, planejava com ela e, conforme sua reação, planejava as aulas, pois as idades eram compativeis. Perceber a aprendizagem acontecendo na fisionomia dos estudantes foi gratificante e a filha queria acompanhar todo o processo! (Estudante C).

Esses registros anunciam uma proposta de política educativa, referindo-se ao que faz sentido, na busca do "inédito viável" de Freire, definido como:

[...] sua auto-inserção crítica na realidade, ou melhor, sua conscientização, faz com que sua apatia se transforme num estado utópico de denúncia e anúncio, um projeto viável. (FREIRE, 1979, p. 46).

É a "leitura do mundo" exatamente a que vai possibilitando a decifração cada vez mais crítica da ou das "situações-limites", mais além das quais se acha o "inédito viável". (FREIRE, 1991, p. 54).

O “inédito-viável” é na realidade uma coisa inédita, ainda não claramente conhecida e vivida, mas sonhada e quando se torna um "percebido destacado" pelos que pensam utopicamente, esses sabem, então, que o problema não é mais um sonho, que ele pode se tornar realidade. (FREIRE, 1991, p. 106).

E nessas ações "novas", na busca de uma escola emancipatória e democrática, exercida no "inédito viável", ocorre o mais belo ato de educar, pois trabalhamos para superar as diferentes formas de discriminação, procuramos estar abertos à comunidade - para que participasse efetivamente na constituição do currículo. Um exercício no ato de aprendizagem que assume o compromisso com a apropriação e o desenvolvimento de conhecimentos significativos a partir das necessidades, conhecimentos e cultura dos educandos. 
Continuando o fluir de depoimentos dos estudantes, salientamos o que um deles expressou:

Precisamos nos aprofundar, pesquisar para dar conta dos desafios com os que não queriam participar. Aprendemos junto com eles e não foi um bicho de sete cabeças. [...] O maior aprendizado foi o planejamento, aprendemos a ter o plano B. Depois disso, faltou tempo para tudo que havíamos planejado. (Estudante J).

E, ainda: "Não sei o que seria da gente sem este processo... A proximidade do professor influencia diretamente na aprendizagem. Eles puderam contar a vida deles para a gente... Aprendemos muito com a troca!". (Estudante K).

Hernandez (2006) nos auxilia a fundamentar o vivido quando traz o conceito de prática pedagógica numa perspectiva dialógica, como sendo a

[...] prática caracterizada pela aprendizagem do professor com seus alunos. Estes, por meio do diálogo, aprendem também que o compromisso da parceria é fundamental em uma relação humana horizontal, que não exclui do professor a responsabilidade de direção do processo de ensinar e aprender, nem exime o aluno da responsabilidade de ultrapassar os limites de sua prática, recriando o espaço-tempo da reflexão e da cultura em relações democráticas e éticas. (HERNANDEZ, 2006, p. 376).

Parece que nossos licenciandos foram tocados pela experiência, o que nos estimula a ampliar a reflexão, levando em conta o que relataram com satisfação:

Estava falando com a minha mãe; até então nunca havia contado o que fazíamos. É parecido com o método do José Pacheco, envolvemos várias áreas do conhecimento e os estudantes comentaram agora que querem fazer vestibular, porque a caneta é mais leve que a pá. (Estudante F).

Vou levar esta experiência para o resto da vida. Todos que passam por uma licenciatura deveriam viver isso. Nos apropriamos do fazer docente! (Estudante J). 
Todas as aulas de licenciatura deveriam ser dentro da escola, na realidade concreta. É um avanço, é perfeito! O olhar da gente é ampliado. (Estudante C).

Embora tenhamos a consciência da extensão do depoimento a seguir, acreditamos na importância de trazê-lo na íntegra, pois reflete a intensidade da experiência para a estudante:

Eu separo minha vida acadêmica em antes do Sertãozinho e depois do Sertãozinho (nome do Colégio). Foi a possibilidade de sair de dentro do espaço fisisico da universidade e ter aula dentro da escola. Vimos que teríamos que desenvolver um projeto com a turma, teríamos uma turma pra gente, com possibilidade de dar aula para os estudantes, fazer avaliação com eles e, ao mesmo tempo, teríamos as nossas aulas. Ou seja, conseguimos integrar o nosso curso com a escola, não precisou separar assim como o estágio é separado.

Ouvir dos estudantes: "eu quero fazer faculdade". Percebemos que conseguimos alcançá-los, especialmente, porque se tratavam de estudantes que tinham aula à noite e que, muitas vezes, são desmotivados... Outros fazem por fazer e não vão estudar com prazer.

Aprendi mais no "Sertão" do que aprendi nos quatro anos de curso, não tenho dúvida alguma sobre isso. Ter mudado para escola me fez pensar que todos os cursos de Licenciatura deveriam fazer isso, ensinar a docência no lugar onde ela acontece, lá na escola.

Então, o que eu vivi na universidade tive oportunidade de multiplicar na escola e acredito que se tivesse vivido esta experiência no meu tempo de escola, tenho certeza, seria outra pessoa. Acredito que fiz diferença lá e penso que foi, disparadamente, a parte mais importante do curso. (Estudante K).

Tudo indica que há uma concepção paradigmática que se estabelece contra a alienação e a sujeição e que procura a autonomia, a autoria, a criticidade e a criatividade, estimulando o sujeito a posicionar-se, envolver-se, comprometer-se. Tudo está interligado, nada ocorre de maneira isolada. O sucesso de uns depende do sucesso de outros e vice-versa. A vida é partilhada e compartilhada, incluindo conceitos como: contexto, vida, autonomia, emancipação, que são ressignificados e atingem novas dimensões, mais harmônicas, abertas, congruentes, ecológicas e colaborativas. 


\section{Um olhar a partir de onde nossos pés pisaram}

E como nos transformamos por meio desses movimentos? Passamos a entender que a formação profissional do professor é um lugar de luta, em constante construção e desconstrução, de diversos modos de ser e estar no fazer docente. E também entendemos que assim é a pessoa, assim são os sujeitos. Nesse processo nos constituímos como professores e como pessoas.

A escuta do outro sobre sua vida já vivida, sobre a vida que ainda anseia viver, foi fundamental para que as relações se estreitassem, para que o olhar também nos aproximasse e construíssemos os laços afetivos, a amizade sincera, a confiança de quem está junto.

Como Freire (1991), entendemos que

[...] no processo da fala e da escuta a disciplina do silêncio a ser assumido com rigor e a seu tempo pelos sujeitos que falam e escutam é um "sine qua" da comunicação dialógica. O primeiro sinal de que o sujeito que fala sabe escutar é a demonstração de sua capacidade de controlar não só a necessidade de dizer a sua palavra, que é um direito, mas também o gosto pessoal, profundamente respeitável, de expressá-la, (FREIRE, 1991, p. 44).

E esse diálogo, aberto, franco, sincero, sobretudo pode traduzir as diversas angústias e ao mesmo tempo desvelar as incertezas. Nos diálogos ancorávamos nossos valores sobre o saber das experiências realizadas por nós na escola, naquele momento.

Fomos pontes, ainda, pois ao iniciarmos o semestre nos encontrávamos com 21 licenciandos e ao término tínhamos 25 . Esses números são significativos no sentido de que constituem os laços para além da escola, realizados entre e pelos licenciandos que estimularam o retorno daqueles que já não estavam mais no curso. Esse ato de construir pontes e de ser ponte permitiu muitas idas e vindas, assumindo que o "caminho se faz caminhando" e nos caminhos atravessamos pontes também. Esses caminhos, que antes desconhecíamos, no exercício pedagógico do ato docente, revelaram-nos a necessidade do confronto para além do conforto do saber individual. Esse momento da formação não é simples, pois saímos do lugar que estávamos enquanto pessoas, enquanto professores, para trilhar o caminho enquanto sujeitos no mundo, com o mundo. 
No sentido de apresentar as nossas fragilidades enquanto práticas do passado, nos expusemos, pois no entendimento do que fazíamos só nos interessava o que poderia haver de futuro na busca pelo inédito viável. Foram momentos delicados na medida em que apresentamos as inseguranças do que já tínhamos realizado e a nossa segurança no que desejávamos realizar. Porque nós, professores, temos uma história de formação e práticas instaladas e o olhar dos estudantes está voltado para essa histórica formação e, também eles, os estudantes, sabem que nem sempre nos dispomos a alterá-las.

No entanto, não há como fazer diferente para ser fiel aos princípios freireanos. Se as perguntas que nos movem já encontram respostas prontas não há busca, no sentido de melhorar a ação docente, é na formação humana que entendemos que a aparição imediata do inédito viável, do utópico, do sonhado, só se dá ao preço do sacrifício do que já se foi. Pois,

[...] não é no silêncio que os homens se fazem, mas na palavra, no trabalho, na ação-reflexão. Mas, se dizer a palavra verdadeira, que é trabalho, que é práxis, é transformar o mundo, dizer a palavra não é privilégio de alguns homens, mas direito de todos os homens. (FREIRE, 1987, p. 44).

Descobrimos que podemos ser os agentes de direito da nossa própria transformação educacional. E o que queremos não se espera, se faz. Pois não basta dizer que uma outra escola é necessária. Precisamos mostrar que uma outra forma de fazer escola é possível.

\section{REFERÊNCIAS}

BONDÍA, J. L. Notas sobre a experiência e o saber de Experiência. Tradução de: GERALDI, J. W. Leituras SME, Campinas, n. 19, p. 20-28, jan./abr. 2002.

BRASIL. Lei no 9.394/96. Lei de Diretrizes e Bases da Educação Nacional. 1996. Disponível em: <http://www.planalto.gov.br/ccivil_03/Leis/L9394.htm>. Acesso em: 18 mar. 2016.

BRASIL. Parâmetros Curriculares Nacionais (PCNs): Ciências Naturais. Secretaria de Educação Fundamental. Brasília: MEC/SEF, 1997.

BRASIL. Guia de livros didáticos: PNLD 2013: Ciências. Brasília: Ministério da Educação, Secretaria de Educação Básica, 2012. 
BRASIL. Diretrizes Curriculares Nacionais para a formação inicial em nível superior. Resolução $n^{\circ} 2$, de $1^{\circ}$ de julho de 2015. Disponível em: <http://www.ead.unb.br/arquivos/ geral/res_cne_cp_002_03072015.pdf >. Acesso em: 22 mar. 2016.

CHARLOT, B. A pesquisa educacional entre conhecimentos, políticas e práticas: especificidades e desafios de uma área de saber. Revista Brasileira de Educação, v. 11, p. 7-18, 2006.

CITOLIN, C. H. Eu falo, tu hablas, vos hablás, nós ensinamos e aprendemos juntos: aulas de línguas em cursos binacionais. Tese (Doutorado) - Universidade do Vale do Rio dos Sinos, São Leopoldo, 2013.

DEMO, P. Avaliação qualitativa. 10. ed. Campinas: Autores Associados, 2010. (Coleção polêmicas do nosso tempo).

FREIRE, P. Conscientização: teoria e prática da libertação - uma introdução ao pensamento de Paulo Freire. São Paulo: Cortez \& Moraes, 1979.

FREIRE, P. Pedagogia do Oprimido. 17. ed. Rio de Janeiro: Paz e Terra, 1987. (Coleção o Mundo hoje, v. 21).

FREIRE, P. Pedagogia da Esperança: um reencontro com a Pedagogia do Oprimido. Rio de Janeiro: Paz e Terra, 1991.

FREIRE, P.; SHOR, I. Medo e ousadia - o cotidiano do professor. Tradução de: LOPEZ, A. Rio de Janeiro: Paz e Terra, 1987.

HERNANDEZ, F. Por que dizemos que somos a favor da Educação se optamos por um caminho que deseduca e exclui? In: SANCHO, J. M.; HERNANDEZ, F. Tecnologias para transformar a Educação. Porto Alegre: Artmed, 2006.

HORTON, M.; FREIRE, P. O caminho se faz caminhando: conversas sobre educação e mudança social. Petrópolis: Vozes, 2003.

KELLER-FRANCO, E.; MASETTO, M. T. Currículo por projetos no ensino superior: desdobramentos para a inovação e qualidade na docência. Revista Triangulo, Uberaba, v. 5, n. 2, p. 03-21, jul./dez. 2012.

MORAES, M. C. Educar na Biologia do Amor e da Solidariedade. Petrópolis: Vozes, 2003.

NÓVOA, A. Vidas de professores. Porto: Porto Editora, 1995.

OKADA, A.; OKADA, S. Novos paradigmas na educação online com a aprendizagem aberta. In: CONFERÊNCIA INTERNACIONAL DE TIC NA EDUCAÇÃO (CHALLENGES, 2007), 5., 2007, Braga. Anais... Braga: Universidade do Minho, 2007. p. 1-11. Disponível em: <http://kn.open.ac.uk/public/getfile.cfm?documentfileid=11833>. Acesso em: 28 jun. 2010.

PARANÁ. Diretrizes Curriculares da Educação Básica Ciências - DCE. Curitiba: Secretaria de Estado da Educação do Paraná, Departamento de Educação Básica, 2008. 
SAUL, A. M. Avaliação. In: STRECK, D. R.; REDIN, E.; ZITKOSKI, J. J. (Org.). Dicionário Paulo Freire. Belo Horizonte: Autêntica, 2008.

SAUL, A. M.; SAUL, A. Mudar é difícil, mas é possível e urgente: um novo sentido para o Projeto Político-Pedagógico da escola. Revista Teias: Dossiê Especial, v. 14, n. 33, p. 102-120, 2013.

SNYDERS, G. Alunos Felizes. São Paulo: Paz e Terra, 1993.

UNIVERSIDADE FEDERAL DO PARANÁ. Projeto Politico-Pedagógico. UFPR, Setor Litoral. 2008. Disponível em: $<$ http://www.litoral.ufpr.br/ppp $>$. Acesso em: 18 mar. 2016.

UNIVERSIDADE FEDERAL DO PARANÁ. Projeto Pedagógico do Curso Licenciatura em Ciências. UFPR, Setor Litoral. 2011. Disponível em: <http://www.litoral.ufpr. br/ciencias>. Acesso em: 18 mar. 2016.

Texto recebido em 16 de junho de 2016. Texto aprovado em 16 de junho de 2016. 
